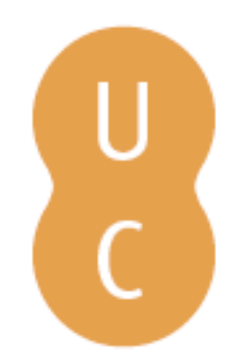

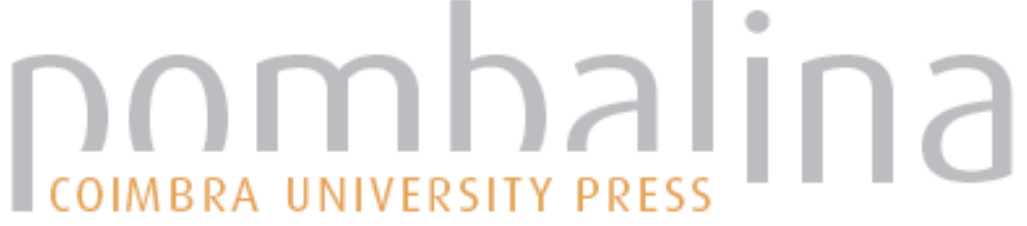

Media, rede e poder: comunicação e democracia

Autor(es): $\quad$ Santos, João de Almeida

Publicado por: Imprensa da Universidade de Coimbra

URL

persistente: URI:http://hdl.handle.net/10316.2/36656

DOI: $\quad$ DOI:http://dx.doi.org/10.14195/978-989-26-0873-0_14

Accessed : $\quad$ 26-Apr-2023 12:36:24

A navegação consulta e descarregamento dos títulos inseridos nas Bibliotecas Digitais UC Digitalis, UC Pombalina e UC Impactum, pressupõem a aceitação plena e sem reservas dos Termos e Condições de Uso destas Bibliotecas Digitais, disponíveis em https://digitalis.uc.pt/pt-pt/termos.

Conforme exposto nos referidos Termos e Condições de Uso, o descarregamento de títulos de acesso restrito requer uma licença válida de autorização devendo o utilizador aceder ao(s) documento(s) a partir de um endereço de IP da instituição detentora da supramencionada licença.

Ao utilizador é apenas permitido o descarregamento para uso pessoal, pelo que o emprego do(s) título(s) descarregado(s) para outro fim, designadamente comercial, carece de autorização do respetivo autor ou editor da obra.

Na medida em que todas as obras da UC Digitalis se encontram protegidas pelo Código do Direito de Autor e Direitos Conexos e demais legislação aplicável, toda a cópia, parcial ou total, deste documento, nos casos em que é legalmente admitida, deverá conter ou fazer-se acompanhar por este aviso.

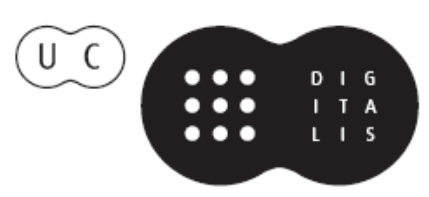


www.uc.pt/ imprensa_uc CONTACTO imprensa@uc.pt VENDAS ONLINE http://livrariadaimprensa.uc.pt JANEIRO 2015
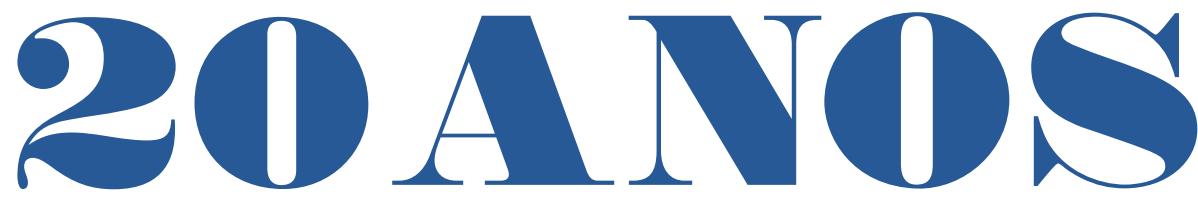

\section{DE JORNALISMO CONTRA A INDIFERENÇA}

TEXTOS DE

Marc Lits, Adriano Duarte Rodrigues, Tito Cardoso e Cunha, José Augusto Mourão, Alberto Pena Rodríguez, Maria Augusta Babo, Daniel Cronu, João Pissarra Esteves, Gilles Gauthier, Heloísa Paulo e Luís Reis Torgal, Alfredo Barroso, António Fidalgo, Nöel Nel, João de Almeida Santos, Juan Luis Cebrián, António Dias Figueiredo, Marina Themudo, Jorge Sampaio, Nelson Traquina, Mário Soares
( livro que agora se apresenta, nasce de dois desígnios fundamentais: por um lado, celebrar duas décadas de ensino do Jornalismo na Universidade de Coimbra e, por outro, partilhar com um público mais alargado um conjunto de reflexões sobre os media, o jornalismo, a comunicação e o espaço público.

Se o ensino superior do Jornalismo em Portugal, relativamente tardio em relação ao resto da Europa, deu os seus primeiros passos no fim dos anos 70 do século passado, ele aparece apenas duas décadas depois na academia coimbrã. Contudo, esta foi, no contexto nacional, a primeira licenciatura em Jornalismo, distinguindo-se, quer em título, quer em objetivos, das licenciaturas então existentes no país. A criação de uma Licenciatura em Jornalismo na Universidade de Coimbra, em 1993-1994, foi, por si, um acontecimento. Com efeito foi necessário que reitor, professores e jornalistas ousassem atualizar a oferta curricular da Faculdade de Letras, oferecendo um curso há muito desejado pela sociedade e pelo mercado, embora desconsiderado por alguns setores da academia. Correndo o risco de omitir alguém, a quem antecipadamente pedimos desculpa, não podemos deixar de recordar os esforços dos jornalistas João Mesquita, João Fonseca, em representação
Todas as gerações, sem dúvida, se julgan para refazer o mundo. A minha sabe, nc que não poderá refazê-lo. A sua tarefa é tc

Consiste em impedir que se desfaça, $p$ unicamente das suas negações A. Camus, Discursos da Suécia (1957)

do Sindicato dos Jornalistas, e de Jorge Castilho, a quem mais tarde se viria associar o nome de Mário Martins, bem como o do então Reitor da Universidade de Coimbra Rui Alarcão, e dos professores João Roque e Luís Reis Torgal. Entre 1993 e 1996, a Licenciatura em Jornalismo funcionou com um Secretariado, que teve um papel executivo e científico nos primeiros tempos do curso na FLUC. Presidido pelo Presidente do Conselho Científico Ludwig Scheidl, este 


\title{
Media, rede e poder: comunicação e democracia*
}

\author{
João de Almeida Santos \\ Universidade Lusófona
}

Permitam-me que, antes de iniciar as minhas reflexões sobre o tema que vos proponho «Media, rede e poder: comunicação e democracia», saúde todos os presentes, Professores e Alunos, e agradeça ao «Departamento de Filosofia, Comunicação e Informação", na pessoa do Prof. Doutor Carlos Camponez, o amável convite que me fez para convosco partilhar este início de ano letivo. É para mim uma grande honra estar na Faculdade onde me licenciei e onde iniciei a minha carreira académica como assistente do Departamento de Filosofia, na especialidade de «Filosofia Política». Eé, para mim, um momento de alguma intensidade emotiva regressar, após 33 anos de ausência física, a um lugar que marcou decisivamente o meu destino. Circunstâncias da vida - a seguir à minha ida para Itália para preparar um doutoramento sobre Antonio Gramsci - levaram-me a seguir outros caminhos que não o do regresso à minha velha Faculdade. Mas nestas circunstâncias ocupava um lugar central o já não poder partilhar a vida e o pensamento com o meu querido Mestre e Amigo Victor de Matos, que, demasiadamente jovem, nos deixou, provocando em todos nós um intenso sentimento de orfandade afetiva e intelectual. Aproveito, por isso, esta ocasião para o relembrar, com ternura, neste meu regresso à nossa Faculdade.

E, agora sim, vamos ao tema.

\section{Media, rede e poder: comunicação e democracia}

\section{Sociedade da Informação}

Proponho-vos este tema- «Media, Rede e poder: comunicação e democracia»porque penso que esta tríade está cada vez mais no centro dos processos sociais atuais, visto não só o caráter nuclear da política na estruturação destes processos, mas vista também a centralidade da comunicação no interior do próprio processo político e, em geral, nos sistemas sociais e nos processos de conquista, consolidação e expansão do poder, quer se trate do poder político quer se trate do poder económico e financeiro ou do poder cultural. Não é por acaso que se designa a sociedade contemporânea como «socieda-

"Palestra Inaugural do Ano Letivo de 2011/2012 do Departamento de Filosofia, Comunicação e Informação da Faculdade de Letras da Universidade de Coimbra. 
de da informação", sucedânea da velha "sociedade da imagem», quando o processo comunicacional estava ocupado, em regime de quase monopólio, pela televisão, pela tal «caixa que mudou o mundo», pelo "príncipe dos mass media», como lhe chamou Denis McQuail (McQuail, 1992), ou, mais prosaicamente, por esse ponto de venda eletrónico instalado em cada lar do universo humano.

\section{I\&C e plataformas móveis multimédia}

De facto, em época de globalização, a «informação e comunicação» (I\&C) é de tal ordem importante que ocupa, nos países desenvolvidos, um lugar entre os primeiros dez setores no produto interno bruto destes países (Jesús Timoteo, 2005). Depois, de um ponto de vista sistémico, a comunicação desenvolve-se hoje em plataformas de tal modo difusas e capilares que é até possível dizer, glosando a célebre inversão do Pirandello dos "sei personaggi in cerca d'autore», que é ela que "constitui" os seus próprios agentes. Sobretudo nas novas e tão difusas plataformas multimédia móveis, onde já é possível comunicar interativamente em todas as dimensões, sem fronteiras, sem lugar e sem tempo. Sem fronteiras, porque a comunicação não conhece barreiras, sem lugar e sem tempo porque ela é universal e instantânea. Plataformas que parece terem capturado os próprios utilizadores, tal a dependência "existencial" que estes mantêm com elas.

\section{A televisão}

Num livro célebre, No Sense of Place. The impact of electronic media on social behavior (New York, Oxford University Press, 1985) Joshua Meyrowitz, que chegou a ser considerado o novo McLuhan, falando dos media eletrónicos, quer dizer, em 1985, da televisão, usava logo no título do livro a expressão «no sense of place», para designar o fim das fronteiras na comunicação, o fim da compartimentação da comunicação entre os grupos sociais (por exemplo, entre crianças e adultos ou entre homens e mulheres) ou mesmo o fim da compartimentação entre planos (por exemplo, entre os bastidores e o palco da política ou entre o privado e o público). Sabemos que este processo se tornou socialmente pregnante a partir dos anos sessenta com o crescimento exponencial da socialização televisiva. Esta compartimentação foi destroçada pelo monitor televisivo, qual terminal qualificado da comunicação/informação, onde tudo conflui sem tempo, sem fronteiras e sem lugar. De algum modo, a televisão, tal como o transístor - fruto da revolução da microeletrónica nos anos '40, veio desestruturar a comunicação tal como a conhecíamos. Também 
o transístor rompeu, em relação à rádio convencional, a geografia situacional do ouvinte, uma vez que alterou a estrutura fixa dos espaços compartimentados da audição, derrubando as paredes, as fronteiras, descomunitarizando a audição e tornando o ato de ouvir rádio um ato «without sense of place», sem sentido de lugar, e sobretudo um ato singular, não comunitário.

É certo que a televisão convencional, à semelhança da velha rádio, ainda continua a processar-se em espaços com fronteiras e em comunidade (por exemplo, ver futebol no Café quando passa na Sport TV e por quem não tem assinatura); mas o essencial é que ela já migrou para as plataformas móveis em rede e, assim, passou a processar-se no interior de outro modelo de comunicação. Tal como a rádio.

Mas a verdade é que a televisão, mantendo durante muito tempo - antes de migrar para a Rede e de passar a processar-se no interior de outro modelo de comunicação - a geografia situacional do telespetador numa posição muito semelhante à da rádio tradicional, o seu sistema operativo interno, já superava as barreiras tradicionais, uma vez que possuía uma capacidade de projeção universal e um dispositivo capaz de impor a sincronia como tempo dominante, rompendo com a compartimentação do real e derrubando fronteiras. Mas possuía também:

a. a capacidade de dilatar e expandir o real para além das suas dimensões físicas (um estádio de futebol é maior em televisão do que na realidade);

b. a capacidade de transfiguração de relações de representação, numa espécie de efeito de proximidade e de banalização: um pivô de telejornal, pelo facto de nos entrar todos os dias pela casa dentro, transforma-se, no real, num velho conhecido muito familiar a quem podemos tratar por tu; ou

c. de alterar a natureza dos fenómenos histórico-sociais, propondo-nos um efeito de repetição/replay daquilo que, afinal, é único e irrepetível: ao perder em pleno estádio de futebol um golo da minha equipa, fiquei por momentos à espera do replay, tal era o hábito de ver futebol na televisão.

Ou seja, a televisão funciona não só como uma nossa prótese cognitiva externa, mas também como uma nossa autêntica prótese interna no plano das nossas relações sensoriais, percetivas e cognitivas. Mas uma prótese que, em funcionamento, produz alterações no sistema operativo do nosso próprio aparelho sensorial, nas dimensões que acima referi: 1. efeito de dilatação e expansão do real; 2 . efeito de proximidade e de banalização; e 3. efeito de repetição/replay do real. Ao que acresce ainda a capacidade de impor a sincronia ou o presente como tempos dominantes, a universalidade da comunicação (sobretudo através da imagem), a descompartimentação dos espaços sociais e a instantaneidade do efeito comunicativo. 
Tudo isto revolucionou a comunicação, que antes era própria da imprensa tradicional ou mesmo de uma rádio que, de resto, também introduziu importantes mutações no processo comunicacional relativamente à imprensa. Ficou famoso o episódio da Guerra dos Mundos, de Orson Wells (Wells, 1990), demonstrando a força imensa dos media, neste caso da rádio.

\section{4. "Broadcasting»: da informação à narrativa}

Mas o que é certo é que o modelo comunicacional estrutural da imprensa, da rádio e da televisão se manteve inalterado. É verdade que os media tradicionais, incluída, afinal, a própria televisão digital ou interativa (que não rompe com o velho paradigma), se movem no interior de um modelo que é sempre o mesmo e que Manuel Castells haveria de designar por modelo «one-to-many», um modelo de tipo broadcasting, centrado na relação emissor-recetor, estímulo-resposta, sujeito-objeto. Como se quiser. Ou seja, o modelo mediático de comunicação é um modelo de tipo vertical, onde a comunicação é sempre gerada (com materiais recolhidos no exterior), trabalhada e difundida a partir de um centro (por exemplo, as redações dos jornais, da rádio ou da televisão) que a difunde para o exterior, para milhões ou, mais precisamente, para as massas, para o público, para os consumidores: "mass communication”. O modelo mediático de comunicação é um modelo próprio da sociedade de massas, de uma sociedade de produtores exógena aos consumidores, separada, não interativa, lá onde, no máximo, o produtor recolhe tendências de consumo para, depois, propor respostas, totalmente acabadas e fechadas, aos consumidores, satisfazendo expectativas que estavam latentes, sim, mas que também foram induzidas, sobretudo através da publicidade e do marketing. É, de resto, neste modelo que se inscrevem as velhas teorias dos efeitos, da teoria da «agulha hipodérmica» até à dos «usos e gratificações». Mas, em geral, todas estas teorias - agenda-setting, "teoria da cultivação», knowledge-gap, "teoria da dependência», "tematização», etc. - se inscrevem neste modelo, que mais não seja porque foram desenvolvidas para explicar a influência (ou a ausência dela) dos velhos media tradicionais. Sobretudo nas campanhas eleitorais. Mas não só. Também é no interior deste modelo que se inscreve o spinning, ou seja, a produção de efeitos especiais sobre a informação de modo a torná-la favorável ao poder que o spin-doctoring está a servir. De facto, este trabalho de spinning foi particularmente concebido não só para uso instrumental de centros de poder, em particular do poder político, capazes de influenciar o establishment mediático, mas também à medida deste modelo da comunicação para massas indiferenciadas (ou reorganizadas em targets para efeitos comunicacionais). 
São conhecidos alguns nomes famosos, como Karl Rove (o operacional de George W. Bush), Alastair Campbell ou Peter Mandelson (os dois principais operacionais de Tony Blair) ou Roger Ailes. É também conhecida a evolução do White House Office of Communications, a partir da presidência de Richard Nixon - e dos graves problemas de imagem que o afetaram e que viriam a determinar a sua queda precoce -, no sentido de uma evolução da informação para uma comunicação em registo narrativo e mesmo ficcional, mais adequado à produção instrumental de efeitos especiais sobre o discurso público do que o registo simplesmente informativo, objetivo e descritivo (veja-se Canel, 2008). E, nesta passagem, a televisão ocupou sempre um lugar muitíssimo relevante. Já com John Kennedy tinham começado as sessões presidenciais de media performance, a que se seguiu a criação de estúdios televisivos internos. Nixon aprendeu a lição. E os outros Presidentes estruturaram a comunicação a partir da plataforma televisiva. Com Obama deu-se um salto e entrou em cena a Rede.

\section{A Rede como espaço intermédio}

Ora, eu creio que, de facto, estamos a conhecer uma mutação estrutural profunda, com alteração radical de paradigma, uma vez que a natureza de um dos lados do binómio comunicacional sofreu uma mutação tão profunda que não é possível conceber a comunicação da mesma maneira. Trata-se da ideia de sociedade de massas, da ideia de cidadão-consumidor de mercadorias simbólicas, da própria ideia de público. Se é verdade que, no domínio dos bens transacionáveis, a natureza da relação entre produtor e consumidor ainda se mantém de certo modo inalterada, já no domínio da Informação e Comunicação esta relação conheceu uma mudança estrutural radical. A tal ponto que Manuel Castells viria a propor um novo e interessante conceito para a designar: mass-self communication (comunicação individual de massas). Ou seja, manteve-se o número, mas alterou-se a estrutura da relação, lá onde o indivíduo ganha um protagonismo que não lhe era reconhecido nem possibilitado pelo modelo mediático de comunicação. Claro, este novo modelo é o modelo digital e reticular, o modelo da rede, que funciona como um ilimitado espaço intermédio onde ocorre a comunicação como fluxo entre variáveis independentes, os agentes da comunicação. Castells usa uma fórmula interessante para designar este novo modelo de comunicação: many-to-many. Ou seja, a mass-self communication é uma comunicação many-to-many que ocorre num imenso espaço intermédio com dimensão ontológica.

Assim sendo, tudo muda na comunicação. É claro que não se trata de uma anulação da comunicação mediática ou tradicional. Esta mantém-se viva 
e forte. Poderia mesmo dizer que ela manter-se-á bem viva e bem forte enquanto houver uma televisão colocada em frente de um sofá. A televisão será sempre uma espécie de correlato do sofá. E a lógica do sofá é certamente uma lógica poderosa. Mas o que já está a acontecer é, de facto, uma alteração substancial do modelo dominante de comunicação, devido à emergência da Rede. De resto, todos sabemos que a comunicação, mesmo a tradicional, está já a migrar para a Rede. Porquê? Não só porque esta se tem vindo a impor a um ritmo verdadeiramente impressionante, mas sobretudo porque o modelo reticular de comunicação (ao contrário do anterior modelo) está em condições de acolher no seu interior, potenciando-o, o velho modelo mediático, com o qual é totalmente compatível. Impressionante, dizia: só um exemplo, por ora. Em Portugal, num ano (de 2010 para 2011), o Facebook cresceu em implantação $11 \%$, passando de $25 \%$ para $36 \%$ da população. E todavia, este novo modelo, compatível com o velho modelo, ao ponto de o poder albergar, introduz, de facto, uma nova lógica que tende cada vez mais a destroçar a velha. Ou seja, se o velho modelo era sobretudo funcional às grandes organizações, que dominavam e tornavam exclusivo o acesso ao espaço público, subalternizando e controlando totalmente o livre exercício da cidadania comunicacional (o famoso gatekeeping), já o novo modelo é mais funcional ao indivíduo singular do que às grandes organizações, que, por isso mesmo, tentam cada vez mais colonizar o espaço digital e reticular, tentando importar para lá as relações de força exteriores. Fenómeno que se verifica até ao nível dos grandes países: veja-se o caso da China, com os seus cerca de 15 mil vigilantes da Rede, e o conflito com a Google. E porque é que é mais funcional ao indivíduo singular? Precisamente porque ela é gratuita e diretamente acessível em todas as suas potencialidades, mas também porque é universal e instantânea; porque, nela, a comunicação é feita entre variáveis independentes (e não na óptica do sujeito-objeto), onde a determinante é a relação e não algum dos dois membros da relação; porque o emissor é simultaneamente recetor e vice-versa (prosumer, é o novo conceito que os identifica) e porque não está sujeita ao chamado gatekeeping, à vontade dos Senhores da Opinião, ao establishment mediático. Tudo isto coloca o cidadão em condições não só de se informar em todas as direções, mas também, e sobretudo, de se protagonizar no espaço público, bastando-lhe para isso apenas capacidade, saber e criatividade.

Como se vê, algo de muito radical está a acontecer com o processo comunicacional, o que não deixa de ter implicações quer no plano das grandes organizações quer no plano da política, sobretudo dos partidos políticos, 
enquanto grandes organizações que são. Sobretudo os que têm expressão parlamentar. É certo que todas as organizações já estão presentes na Rede. Mas, na generalidade, não estão lá com a lógica da rede. Estão, sim, com a lógica inscrita na relação emissor-recetor ou sujeito-objeto. Porque, afinal, a lógica da Rede é mais a do "poder diluído", como diria Jesús Timoteo, ou a do micropoder, como diria Javier Cremades. O que pretendo dizer é que as grandes organizações, media ou partidos, estão modeladas, em termos de comunicação, com a lógica inscrita na relação emissor-recetor, sujeito-objeto, produtor-consumidor, estímulo-resposta e não com a lógica do poder diluído, como acontece na Rede. É por isso que elas tentam colonizar o espaço intermédio, replicando as relações de força externas. Entre estas organizações estão certamente os partidos políticos, mas estão também os grandes media. Quando se procurou caracterizar os partidos que se começaram a estruturar de uma nova forma, nos anos oitenta, e penso por exemplo nos trabalhistas ingleses e no New Labour de Neil Kinnock e Tony Blair, o nome que se encontrou foi Catch all Parties (a fórmula é de Kirchheimer). Agora, para designar os correspondentes media também seria possível falar em Catch all Media, dadas as semelhanças entre os grandes partidos com vocação governativa e os grandes media comerciais: a procura do grande centro e da chamada middle class. São os media que Hallin e Mancini, em Comparing Media Systems. Three models of media and politics (Hallin e Mancini, 2004), identificam com o modelo liberal e que eles consideram estar destinados a impor-se como modelo dominante. Estes media, tal como os partidos, enquanto organizações, libertaram-se muito da pressão político-ideológica, da representação de classe, olhando mais para a sociedade como um mercado, intensificaram o nível de profissionalização, centralizaram o poder decisional, deixaram de ser portadores exclusivos de projetos político-culturais para passarem a ser mais intérpretes das expectativas difusas do mercado eleitoral ou das audiências. Tudo isto é verdade e representa uma evolução interna da narrativa mediática e política. Certamente, mas, entretanto, a Rede veio romper com esta evolução linear e com este modelo próprio da sociedade de massas, ao ponto de ambos, partidos e media, terem já iniciado um intenso processo de migração para a Rede. Barack Obama, num modelo altamente personalizado de exercício da política, mas com um imponente back-office partidário na retaguarda, o Partido Democrata, na sua campanha eleitoral conseguiu, através da Rede, $67 \%$ do total dos cerca de 600 milhões de dólares da sua campanha. O que diz muito sobre a importância da Rede. Se verificarmos a taxa de cobertura da Rede - os dados são da Internet World Stats - nos principais países 
desenvolvidos ficamos impressionados com os números, em particular se comparados com a taxa de leitura da imprensa. Falamos de níveis de cobertura da Rede equivalentes a 48\%, em Portugal, a 49,2\%, em Itália, a 62,2\%, em Espanha, a 69,5\%, em França, a 77,3\%, nos USA, ou a 79,9, na Alemanha. Mas, se fizermos uma comparação entre as taxas de cobertura da Rede e da imprensa escrita (jornais, sobretudo) em Portugal e as que se verificam nos outros países, o diferencial é enorme no que toca às taxas de cobertura de jornais, sendo, todavia, muito menor no que toca à Rede. E menor ainda se olharmos para o crescimento exponencial que se está a verificar no Facebook. Vejamos alguns dados:

Enquanto Portugal exibia, em 2000 - e note-se que a tendência tem sido de queda progressiva, como, por exemplo, se pode verificar com o número de exemplares de circulação total por edição perdidos pelo Público e pelo Diário de Notícias entre 2003 e 2010: cerca de -40\% para ambos (Público-39.69\%, Diário de Notícias -40.86\%)-, proporcionalmente, em leitores de jornais, somente 11,5\% dos leitores noruegueses, já em relação à Rede a penetração portuguesa correspondia (em 2010) a 50,7\% da penetração norueguesa. Algo equivalente se passa em relação aos USA: $31,37 \%$ dos leitores americanos de jornais, mas já $62,2 \%$ da penetração da Rede americana (em 2010). Em relação a Espanha, a 44,4\% dos leitores espanhóis de jornais (dados de 2000) corresponde 76,8\% da penetração da Rede espanhola (dados de 2010). E o diferencial tem vindo a aumentar irremediavelmente...

\section{Partidos, media, Rede e democracia: da simetria imperfeita à si- metria perfeita.}

A política democrática não pode deixar de refletir esta mutação estrutural. Julgo ter demonstrado, num ensaio que publiquei na Rede, que o modelo mediático de comunicação só é simétrico relativamente ao sistema representativo no plano do emissor, ou seja, o modelo mediático ocupa um lugar equivalente ao do modelo partidário, sendo ambos emissores (um, de informação, outro, de propostas políticas), mas não é simétrico no plano do recetor, ou seja o leitor/ouvinte/espetador não equivale perfeitamente ao cidadão, porquanto aqueles não possuem uma verdadeira função constituinte relativamente ao sistema mediático como, pelo contrário, acontece com os cidadãos eleitores relativamente ao sistema político representativo. De facto, uma das críticas que hoje é feita à política é a de ter permitido (colaborando ativamente nisso) uma autêntica transmutação do cidadão ativo em mero espetador da representação política, quando o que deveria ter acontecido era a transmutação do espetador em cidadão ativo. Foi essa, de resto, a intenção de Bertolt Brecht quando introduziu 
o conceito de efeito de distanciação (entfremdungseffekt). Ora, o que veio a acontecer com a Rede é que, nela, o internauta também possui, tal como o cidadão, capacidade constituinte, verificando-se, na minha perspetiva, uma simetria perfeita entre os dois modelos: da Rede e da democracia representativa. Ou seja, o que se verifica é que o clássico modelo de funcionamento dos partidos e dos media não era totalmente simétrico relativamente à estrutura de funcionamento prevista pela democracia representativa. O que, pelo contrário, viria a acontecer com a Rede. E esta já está aí com todas as suas virtualidades. $\mathrm{O}$ que, pelo contrário, ainda não temos é o equivalente político, visto que a lógica organizacional dos grandes partidos ainda continua a prevalecer sobre a lógica do "poder diluído". Mas, mesmo assim, e ainda que se admita que o modelo partidário acaba sempre por ter como destinatário, a jusante, um cidadão com poder constituinte, a verdade é que no modelo mediático de comunicação o recetor mantém-se passivo, não tendo capacidade constituinte sobre o espaço público, que mais não seja porque está sempre sujeito ao poder de gatekeeping exercido inapelavelmente pelo establishment mediático. Ou seja, a simetria mantém-se imperfeita no plano do recetor: em qualquer caso, e ainda que a subjetividade partidária tenha vindo, a montante, a reduzir cada vez mais o cidadão a um mero consumidor de produtos políticos, a verdade é que $o$ cidadão mantém sempre, a jusante, uma capacidade constituinte, que repousa na sua capacidade de voto. E ainda que, acrescente-se, a legitimidade de mandato já não seja o que era, isto é, tenha sido substituída, precisamente devido ao poder dos media, por aquela que eu designo como «legitimidade flutuante», ao sabor das flutuações da opinião pública. E ainda que, diria mais, ao cidadão não tenha restado senão uma função designativa, ou seja, a de escolha do representante, sem correspondente e eficaz legitimidade de mandato.

Mas então, com a nova realidade da Rede, verifica-se que o "poder diluído" é aquele que melhor correspondequerà Redequerà democracia representativa?

Aproximamo-nos assim de novas formas de democracia direta?

\section{A Rede, a democracia e a ética da responsabilidade}

O que pretendo demonstrar com este discurso é que tudo aponta para a inauguração de um novo ciclo na secular evolução da democracia. E esse novo ciclo tem tudo a ver com a revolução na comunicação, com uma radical mudança de paradigma, lá onde a centralidade do indivíduo descoberta e proposta com a instauração do sistema político representativo viria a conhecer um impulso decisivo, ao resolver o handicap de que continuava a ser portador o cidadão eleitor, ou seja, em linguagem convencional, o recetor de 
informação/mensagens e propostas políticas. É certo que os media, da imprensa ao audiovisual, foram decisivos para a consolidação das duas fases de desenvolvimento da democracia, que são conhecidas como "Democracia de partidos» (século XX) e «Democracia do público» (finais do Século XX e início do Século XXI) (Manin, Minc), e consideradas muito importantes para a evolução da própria política democrática. Mas foi com a emergência da Rede, enquanto «espaço intermédio» com densidade ontológica, que a individualidade se pôde começar a informar livremente à escala universal e livre de barreiras físicas à satisfação da sua curiosidade, mas também a exprimir publicamente com a liberdade de quem não tem de pedir autorização aos guardiões do espaço público, num registo que, afinal, será eticamente bem mais exigente do que todos os códigos éticos que conhecemos até aqui. Um registo que é equivalente ao que marca o gesto singular do cidadão quando, na solidão da urna de voto, exerce o seu direito de reconstituição e de relegitimação do poder no signo daquele que é certamente o lapidar princípio da democracia representativa e que foi formulado por Kant, na Crítica da Razão Prática e na Fundamentação da Metafísica dos Costumes, com o nome de «imperativo categórico»: «age como se a máxima da tua vontade pudesse valer ao mesmo tempo e sempre como princípio de uma legislação universal». Ou seja, no voto, o princípio da liberdade está conjugado à máxima potência com esse outro tão esquecido princípio: o princípio da responsabilidade. Neste sentido, e quer no plano da comunicação quer no plano da decisão político-eleitoral, a lógica da rede induz uma exigência de responsabilidade muito mais intensa e ampla do que a lógica mediática, porque ela interpela o cidadão singular para além das afinidades corporativas reunidas em torno de um qualquer "código ético», "código deontológico» ou, como eu prefiro chamarlhe, «esquema normativo de referência». E esse cidadão singular é cada vez mais um centro complexo de decisão, de informação e de comunicação, lá onde comunicação e política convergem em unidade perfeita. É por isso que eu digo entre a Rede e a Democracia existe uma simetria perfeita.

\section{Conclusão}

Finalmente: através da Rede podemos ver que a comunicação não é uma variável exógena ao sistema democrático, mas sim uma variável interna do próprio sistema. E tão importante que acabará por determinar mutações tão profundas no sistema que levarão a uma autêntica integração e superação dos modelos até agora conhecidos: a democracia evoluirá de tal forma que acabará por produzir uma nova forma de democracia que, sem destruir o sistema representativo, possa ao mesmo tempo incorporar a democracia 
direta, agora não através de mecanismos imperativos de natureza comunitária ou sequer dos clássicos meios já praticados, como, por exemplo, o referendo, mas sim através de um recentramento do papel do indivíduo singular, enquanto cidadão ativo, na regular reconstrução da legitimidade do poder, lá onde o indivíduo, pela primeira vez na história, não é dissolvido na comunidade ou nessa multidão solitária que constitui materialmente a sociedade de massas. É neste registo que eu valorizo a intuição genial de Manuel Castells quando nos propõe esse feliz conceito de mass self communication, de «comunicação individual de massas».

\section{Referências}

CANEL, María José (2008). Comunicación Política. Una guía para su estudio y práctica. Madrid: Tecnos.

HALLIN, Daniel e MANCINI, Paolo (2004). Comparing Media Systems. Three models of media and politics. Cambridge University Press [tradução italiana: (2009), Modelli di giornalismo. Mass media e politica nelle società occidentali. Roma-Bari: Laterza; portuguesa: (2010). Sistemas de media: estudo comparativo. Três modelos de comunicação e política. Lisboa: Livros Horizonte.

MCQUAIL, Denis (1992). Media Performance. Mass communication and the public interest. London-New Delhi: Sage Publications.

MEYROWITZ, Joshua (1985). No Sense of Place. The impact of electronic media on the social behavior. New York: Oxford University Press.

SANTOS, João de Almeida (2013). A Rede e a Democracia: uma simetria perfeita? In: joaodealmeidasantos.com.

TIMOTEO, Jesús (2005). Gestión del Poder Diluido. La construcción de la sociedad mediática (1989-2004). Madrid: Pearson.

WELLS, Orson (1990). La guerra dei Mondi. Bologna: Baskerville. 